\title{
REFERENCE REVIEWED AND RE-ENVISIONED: REVAMPING LIBRARIAN AND DESK-CENTRIC SERVICES WITH LIBSTARS AND LIBANSWERS
}

\begin{abstract}
The first section of this article reviews the literature on the changing face of reference, beginning with a discussion of the national decline in reference transactions, its causes, and the likelihood that online reference services might one day halt or reverse the decline. It then analyzes definitions of the term "reference," pointing to a disconnect between those definitions and much of the work that actually takes place at reference desks. Next, critiques of desk-centric models of reference are examined, followed by a discussion of the persistence of the desk in so many academic libraries today. The analysis of the literature in section one informs the reenvisioning of reference services at CPP discussed in section two. Specifically, section two describes and assesses CPP's reference desk staffing shift from librarians to LibStARs (Library Student Assistant Researchers) and our implementation of LibAnswers in an effort to automate some reference transactions. The paper ends with an overview of the benefits of these new initiatives.
\end{abstract}

\section{INTRODUCTION}

In 1986, Ford offered reference librarians some cautiously worded but nevertheless provocative advice, encouraging them "to begin to think the unthinkable, exploring alternatives and possibly eliminating the reference desk." ${ }^{1}$ By 1994, Summerhill had responded to the call, arguing that "traditional reference services are not cost-effective" ${ }^{2}$ and as a result, libraries should "detach reference services from the reference desk." 3 The following year saw an article by Ewing and Hauptman proclaiming, "traditional academic reference service...does not need to be rethought or reconfigured, it needs to be eliminated," ${ }^{4}$ and soon thereafter a response from 
Lewis declaring, “Traditional reference service is already dead. If we have not done so yet, we should bury it."5 It turned out, however, that traditional reference services, and the reference desk specifically, were "not quite dead yet," ${ }^{6}$ persisting widely in academic libraries well into the twenty-first century. However, calls for the end of the reference desk resumed again in earnest in 2007. Bell, for example, posed the question, "Who needs a Reference Desk,” which he followed with a "modest proposal” calling for its elimination. ${ }^{7}$ That same year, Sonntag and Palsson confidently asserted "It's unquestionably time to eliminate the reference desk." ${ }^{8}$ While previous critiques of the reference desk and declarations of its demise appear to have had little impact on the persistence of reference desks in academic libraries, the global financial crisis that began in 2007 has made it impossible for many libraries to continue on their current paths, challenging them to take Summerhill's dated (1994) but decidedly relevant advice to view "these difficult times as an opportunity to reassess priorities and reassess modes of operation." ${ }^{9}$ Such was the case at the University Library at Cal Poly Pomona (CPP), where in 2008, budget woes, a shrinking staff, and decreasing traffic at the Research Help Desk incited the Reference, Instruction, and Collections Department to join the ongoing professional conversation about the future of reference, examining our current service model and exploring potential alternatives.

The first section of this article reviews the literature on the changing face of reference, beginning with a discussion of the national decline in reference transactions, its causes, and the likelihood that online reference services might one day halt or reverse the decline. It then analyzes definitions of the term "reference," pointing to a disconnect between those definitions and much of the work that actually takes place at reference desks. Next, critiques of desk-centric models of reference are examined, followed by a discussion of the persistence of the desk in so many academic libraries today. The analysis of the literature in section one informs the re- 
envisioning of reference services at CPP discussed in section two. Specifically, section two describes and assesses CPP’s reference desk staffing shift from librarians to LibStARs (Library Student Assistant Researchers) and our implementation of LibAnswers in an effort to automate some reference transactions. The paper ends with an overview of the benefits of these new initiatives.

\section{WHAT'S WRONG WITH REFERENCE?}

In his frequently cited 1984 article, Miller posed the question "What’s wrong with reference?" and then identified "reference sprawl" as the source of a "malaise" that was infecting “reference departments everywhere.” ${ }^{10}$ Our ever-expanding services, he argued, were leading to burnout and service that "is probably not very good." ${ }^{11}$ For Miller, the "real problem facing us is not the generation of more business, but proper management of the business we have already generated.”12 Nearly 30 years later, some would say we are still dealing with reference sprawl, as many academic libraries offer more types of reference services than ever before (reference desk, email, chat, texting, consultations, etc.). However, today, the question "what's wrong with reference" is inextricably linked to the dramatic decline in reference transactions that began to come into focus during the last decade of the $20^{\text {th }}$ century and the first decade of the $21^{\text {st. }}$ Some viewed this trend as part of a larger decline in the use of physical libraries in general. In his 2001 Chronicle of Higher Education article, for example, Carlson memorably described academic libraries as "deserted" due to the advent of the Internet and the emergence of digital libraries. ${ }^{13}$ Many librarians bristled at this claim, citing rising gate counts and usage statistics as proof that their libraries remained vital and relevant, functioning as the social and intellectual centers of their respective campuses. ${ }^{14}$ Reference statistics, however, rarely could be called upon to support the case for the rebounding library. ${ }^{15}$ Instead, Association of Research Libraries (ARL) statistics 
from the years 1991 through 2004 documented a 35\% decrease in reference transactions. ${ }^{16}$ Other libraries documented more dramatic declines; Northern Illinois University Libraries reference transactions declined by 61\% from 1996 to 2002, the University of Maryland Libraries’ declined 64\% between 1995 and 2004, ${ }^{17}$ and The University of Arizona Library’s dropped 88\% from $1991-2004 .^{18}$

This trend was also borne out at Cal Poly Pomona, a public university that is part of the 23-campus California State University system. ${ }^{19}$ In 2008, the CPP University Library completed a \$58.5 million expansion and renovation that led to increased gate-counts, belying Carlson’s depiction of the deserted library, but CPP's reference statistics followed the national trend, declining sharply. Reference desk statistics specifically reveal a dramatic decrease in traffic, from 73,757 desk transactions during the 1990-1991 academic year to 12,952 during 2010-2011. These figures translate into an average reference desk transaction decline of just under $8 \%$ a year for a dramatic $82 \%$ decline over the 21-year period. When we look beyond the desk to total reference statistics (desk, chat, email, private research consultations, etc.), the decline is still dramatic, decreasing an average of over $6 \%$ a year and culminating in a 75\% decrease over 21 years. $^{20}$

Most librarians attribute the decline in reference transactions to the advent of the Internet and the ease with which users can find information online without entering a library. In the past, neither finding discrete units of information (e.g., what was the population of London in 2001?) nor finding scholarly sources on a research topic (e.g., I need 5 peer reviewed articles on Macbeth) were particularly easy tasks. Reference desk traffic was high because searches had to be done with physical materials in the library, and the process for using various indexes was not at all transparent. Today, students who want to know the population of London or some other 
factoid will Google it. As LaGuardia conceded back in 2003, librarians do not "get some of the quick, look-up-type questions because users just check it out on Google.” ${ }^{21}$ Campbell similarly asserted that same year that students and faculty alike "are vastly more likely to turn to these search engines than they are to enter a library and ask a question today.” ${ }^{22}$ Framing the provision of information services as a competition between search engines and reference librarians, Campbell claimed, "The search engines have already won the competition.”23

Similarly, basic academic research has gotten easier as well. Most students today do not need to learn what a paper index is, where it is located, and how to use it to begin finding articles on their topics. They do not have to learn about controlled vocabulary when inputting a few keywords will generally suffice, nor do most even have to come to the library building, let alone navigate its physical space in search of the locations of mysterious objects such as "bound periodicals” and “microfiche.” When library materials went online for public use, reference desks still received many questions from students conducting academic research because the systems were unfamiliar and not particularly user friendly. However, vendors and library webmasters have made databases and library websites increasingly intuitive and easier to use, decreasing the amount of user queries. As Ryan observes, "in most cases students can enter a few keywords on their topic, check the 'full-text' and 'peer reviewed' limiter boxes and get more articles than they can digest.”24

Others argue that the growth of library instruction/information literacy programs has also contributed to the decrease in reference questions, empowering students to become independent information seekers. Bell, for example, refers to information literacy instruction as a form of “pre-emptive reference.”25 Sonntag and Palsson claim that information literacy instruction “embedded within a specific class or subject matter, with plenty of hands-on activities for 
students to really learn what is being taught, can eliminate many questions the students would have had while doing research for that class. This is the new form reference work is taking; only it’s called instruction." ${ }^{26}$ In this framework then, meaningful, well-timed, course integrated information literacy instruction empowers learners and reduces the amount of questions that they might otherwise ask at places like a reference desk. Questions asked and answered in library instruction sessions are generally not considered "reference" questions nor included in reference statistics, which also contributes to declining reference transaction numbers.

\section{Will Online Reference Services One Day ReVerse the Decline?}

In his 2005 response to the questions raised by Carlson’s 2001 depiction of the “deserted library,” Martell argued that declines in a variety of services, including reference, "are deeper and more widespread than generally recognized” and that they are likely to continue. He also predicted, “reference transactions will probably remain soft until on-line reference services appear in full force.”27 He speculated that some service areas had the potential to see their numbers increase when in-person and online transactions were added together. ${ }^{28}$ Since 2005, libraries have continued to see the growth of online reference services, from consortial services like QuestionPoint to advanced FAQ, texting, and email services provided by companies like SpringShare (e.g., LibAnswers). Moreover, librarians have shifted their statistics gathering practices from an almost entirely reference desk-centric focus to one that accounts for a variety of types of reference transactions, including face-to-face interactions at a reference desk and consultations with reference librarians in their offices, in addition to online chat, email, texting, and automated question-answering systems.

At Cal Poly Pomona, we have indeed seen online reference transactions (email, chat, LibAnswers) begin to make up an increasingly larger percentage of total reference transactions, 
from $0.3 \%$ of total yearly transactions when we began recording online reference transactions in 1998/99, to $28 \%$ in $2010 / 11 .{ }^{29}$ It is also worth noting that although CPP's total reference transaction data for the 21-year period from 1990/91-2010/11 is primarily characterized by a dramatic decline in total reference transactions, 2009/10 and 2010/11 showed 5\% and 9\% increases respectively over the previous years, and these increases were fueled in part by online reference transactions. It is too early to tell, however, whether these increases will continue at $\mathrm{CPP}$ or whether they might be part of a larger national trend. Moreover, to put these figures in perspective, the total number of CPP reference transactions for 2010/11 was 18,517, which still amounts to nearly a 56\% decrease in total reference transactions from 2000/2001 and a 75\% decrease from 1990/1991. In sum, while online reference transactions have tended to increase over the past ten years at CPP and total reference transactions have seen some modest gains in the past two, it remains unclear whether online reference transactions will significantly reverse the larger trend of decline that has characterized the last 20+ years of reference statistics at CPP.

\section{RESPONDiNG TO CHANGE}

While some librarians lament the fact that reference transactions are declining and argue that we need to find new ways to generate business, others suggest that the proliferation of different types of reference services could also be seen as evidence of Miller's “reference sprawl.” ${ }^{30}$ We are continuing to offer patrons more ways to access reference services, but which ones are actually being used? As we expand our services, doing more with less, how is service quality affected? Are libraries today maintaining what Miller referred to as the "organizational fiction” that "we can continue to do everything for everybody, and do it well”? ${ }^{31}$ Are all of our reference services needed and valued by enough of our users to make the provision of them cost- 
effective? Are we assessing our reference services and do we make decisions about them based on evidence?

Addressing such questions can be challenging, but many librarians are nevertheless proactively confronting them, arguing that we should “embrace transformative change,” “innovate for the future,” and "abandon current outdated and dying practices.”32 Summerhill provided an early model for how to do so effectively in the reference context. Following Peter Drucker’s change management advice, she encourages librarians to carefully examine reference services, asking themselves a series of questions:

- Is the "product” worth producing?

- Do the processes involved in providing reference services make sense?

- If they do make sense or if some revised version of them makes sense, then the question becomes "Is there a more cost-effective way to provide the services at the desired level of quality?”33

\section{What We Talk About When We Talk About Reference}

To answer such questions, Summerhill argues that we first need to define what constitutes our "product.” Put another way, what is it that we are attempting to offer to our users? Summerhill provides a succinct definition: "reference services may be defined simply as a facilitation of the connection between researchers and the information they desire or need.”34 This definition includes activities such as reference transactions-active interactions between library staff and patrons, whether face-to-face or online, synchronous or asynchronous—but it also includes the behind the scenes work of designing, organizing, and presenting information and resources in such a way that makes it possible for users to find information on their own. The design of an intuitive and user-friendly library website, for example, facilitates the 
connection between researchers and the information they need, and as such, is also reference work.

The Reference and User Services Association’s (RUSA) 2008 definition of reference work is more explicit about reference services encompassing more than just the reference transaction: "reference work includes reference transactions and other activities that involve the creation, management, and assessment of information or research resources, tools, and services." ${ }^{35}$ RUSA goes on to clarify that reference work could potentially include a wide variety of tasks, such as developing research collections, guides and tutorials, catalogs, databases, websites, and search engines that researchers can use independently. It also includes the assessment of those resources and services, highlighting strengths and weaknesses and recommending and implementing changes to various tools, such as the library website, catalog, and databases.

RUSA also defines reference transactions specifically as "information consultations in which library staff recommend, interpret, evaluate, and/or use information resources to help others to meet particular information needs. Reference transactions do not include formal instruction or exchanges that provide assistance with locations, schedules, equipment, supplies, or policy statements." ${ }^{36}$ Like Summerhill's definition, RUSA's also emphasizes the goal of helping patrons find information, but RUSA's definition is particularly notable for delineating what reference transactions are not. They are not about providing directions; scheduling; helping students operate printers, copiers, and computers; supplying staples, pens, and paper; or explaining library policies. These are precisely the kinds of questions, however, that predominate at most reference desks. 
In 1995, Ewing and Hauptman observed, “many critics who have studied reference interactions have noted that an extremely high percentage are directional or simplistic in nature" and could be answered "by moderately capable high school graduates" provided with "a little inhouse training and an apprenticeship program.”37 Although they did not cite any sources, there are many such studies that substantiate this claim. St. Clair and Aluri’s 1977 study, for example, analyzed questions posed at the reference desk at the University of Nebraska at Omaha on 44 randomly selected days and determined that $44.1 \%$ of the questions were directional, $18 \%$ were instructional, 32\% were reference, and 5.9\% were extended reference. After analyzing the professional skills required to answer these questions, they concluded that "carefully trained nonprofessionals at the reference desk can competently answer 80 percent of these questions.”38 More recent studies of reference transactions have drawn similar conclusions. For example, Carlson reported that approximately 41\% of reference questions at Temple during 2005-2006 were directional and only 5\% were complex research questions. ${ }^{39}$ Similarly, the University of Arizona logged questions for two weeks in 2004 at all of their service sites and found that $70 \%$ of the questions could be answered by trained students and that just $4 \%$ of the questions required the services of a subject specialist. ${ }^{40}$ Ryan's 2008 study of 6959 reference transactions logged at the reference desk by four full-time and two part-time librarians, found that $64 \%$ of questions were directional or technology/machine related. Only $11 \%$ of the questions fell under the research category, and those questions "varied widely in complexity." 41 While the study did not speculate about how many of the questions labeled as "research" could be answered by welltrained students or staff, it nevertheless concluded that $89 \%$ of the total transactions studied could be handled by non-librarians “trained in basic knowledge of the library's electronic resources, hardware and software issues, and procedures and polices, with an occasional referral 
to a librarian.” 42 Similarly, Cal Poly Pomona reference desk statistics over a 21 year period, from 1990/91 to 2010/11, indicate that over $90 \%$ of the questions were either directional (35\%) or could be answered in less than 6 minutes (56\%). Only 3\% of the total questions required 10 or more minutes to answer.

\section{DEFINITIONAL DISCONNECT}

Studies indicating that the majority of questions fielded at the reference desk could be answered by non-librarians support Steven Bell’s observation that “More and more front-line librarians are finding that what they thought would be reference work is turning out not to be reference work." 43 That is, for many librarians, the "reference desk" is virtually synonymous with reference work. It looms large not only as a dominant symbol of the profession but also as an actual place where librarians “do” reference. This remains the case for many librarians despite:

1) professional definitions of reference work that position reference transactions (regardless of where they occur) as only one facet of reference and

2) evidence indicating that most reference desk transactions do not meet our own professional definitions of reference work.

This conflation of reference work with the reference desk is understandable given the desk’s long history and the amount of time many librarians have spent there over the course of their careers. Many reference librarians are scheduled on the reference desk 10+ hours a week, so it is unsurprising that "working the desk" is often conflated with reference work generally. However, because much of what happens at the reference desk is not actually reference work, it is important to dislodge our understanding of reference from the desk. Helping students with printing issues, refilling the stapler, providing directions to various library and campus locales, 
and explaining library policies are tasks that do not involve "the creation, management, and assessment of information or research resources, tools, and services," nor are they "information consultations” in which the library staff uses, recommends, interprets, or evaluates information resources to help meet information needs. In short, such transactions do not meet the definition of reference work and assigning librarians to sit and wait at a desk to primarily answer these types of questions is a poor use of human resources. Bell concurs, arguing, "doling out software help and fixing paper jams, two frequent reference desk tasks these days, squanders the talent and expertise of skilled librarians.”44

\section{DOES THE DESK STILL MAKE SENSE (DID IT EVER)?}

Most librarians would agree that facilitating "the connection between researchers and the information they desire or need”45 remains an important goal for academic libraries, that it is a "product” that is worth producing because it supports the teaching, learning, and research missions of our larger institutions and contributes to students’ academic success. However, after examining the value of our product, reference services, Summerhill encourages librarians to then turn a critical gaze to the "processes involved in providing our services," asking not only if they still make sense but also whether they ever did. If the process for delivering a service is determined to no longer make sense, the question becomes, is there a more cost-effective and efficient way to provide high quality service to our patrons?

When we examine the reference desk as a medium through which we provide reference services, there are many arguments to support the idea that the reference desk historically did make sense. Bell, for example, points out that the traditional reference desk service “was designed to answer shorter, less-time consuming 'ready reference' questions-the type that could be easily answered by consulting the large number of reference volumes contained in the 
library's reference collection.”46 The high volume of reference transactions could be seen as attesting to a real need. During a time when information was scarce and its organization was not particularly intuitive, librarians were able not only to collect expensive reference books in which answers to a wide-range of questions resided but also to organize resources, navigate the organizational system, and ultimately find answers to patrons' queries—-tasks most patrons could not have accomplished on their own.

\section{QUESTIONING THE COST}

However, not everyone would agree that the reference desk played an essential function in the days prior to the Internet. In 1995, for example, Ewing and Hauptman argued, "the demise of reference service will not occur merely because new technologies are introduced." ${ }^{47}$ They claimed instead that "the seeds for its demise existed long before computers entered libraries." 48 The problem? Many reference interactions have always revolved around directional and/or simple questions that are relatively easy to answer, and as such, they never required the expertise of librarians with advanced degrees. The implication here is that staffing the reference desk with professional librarians is not an effective use of human resources and as such it is a fiscally irresponsible way to run an organization. "How soon will it be" Ewing and Hauptman questioned, "before some administrator, exercising fiscal responsibility, or legislator, responding to constituent demands for fiscal restraint, questions the value added to education through reference service?”49

That same year, Summerhill also highlighted fiscal issues in her analysis of the reference desk, using language that is particularly pertinent today: "With the continuing recession and the deficit crisis, it is clear that since society is long past the era of 'having it all,' priorities need to be clearly defined." ${ }^{50}$ She argued that desk-based, sit-and wait, reference service is inherently 
expensive and inefficient due to the idle time that is inevitable in any queuing service model.

While some librarians bring out work to do at the desk during down times in an effort to be more efficient, engaging in other work can make them seem less approachable, thereby decreasing the effectiveness of the service and the chances that students will utilize it. Summerhill also pointed out that many reference desk transactions are directional, simple, or clerical in nature, arguing that reference librarians "are too highly paid to be doing work on a regular basis that easily could be done by a paraprofessional or a clerical assistant." ${ }^{51}$ In a particularly incisive passage, she observed, "telling someone the location of a restroom is a courtesy, not a transaction worthy of being recorded with a tick mark on the reference statistics sheet." 52 "Reference librarians,” she argued, “can ensure the availability of cost-effective information services by concentrating on those high-level functions that their education, training and experience qualify them to do.”53 Summerhill concluded that an appointment model where reference transactions occur in librarians' offices is more cost-effective; librarians end up spending more time on task rather than sitting and waiting for questions. The appointment model also allows librarians to be better prepared for the transaction, increasing the quality of the service. ${ }^{54}$

While Summerhill focused on the inefficiencies inherent in the reference desk model that make it cost-ineffective, Ryan’s study of the reference desk at Stetson University not only examined the types and frequency of questions coming to the reference desk but also attempted to quantify transaction and service costs. Her study revealed that the library spent approximately $\$ 49,328$ in salaries to fund reference desk coverage over 8 months (approximately $\$ 60,000$ annually). She then divided this figure by the number of questions, revealing that the library spent an average of $\$ 7.09$ per transaction. Ryan notes that this “does not seem particularly expensive to answer the 784 'research’ questions (\$5559),” but the \$7.09 also applied to “each of 
the 2528 times that a printer cartridge was changed, or a paper jam fixed, or directions were given to a building across campus (totaling $\$ 17,924) .{ }^{\prime 55}$ These costs would have been much less if the desk was staffed by a lower paid staff member or student, and the questions asked would have been better aligned with a student or staff member's level of expertise. The study also revealed that while Stetson librarians answered approximately 20 directional, machine, and technology related questions per day, they only answered an average 3.6 research questions daily. The study thus calls into question the efficiency of staffing a desk 12 hours a day with professional librarians to handle less than four research questions. ${ }^{56}$

\section{QUESTIONING THE VENUE}

In addition to the cost issues, there is also the question of whether the reference desk is an effective place to actually do real reference work. Freides argued in 1983, "the reference desk works best for directional questions and requests for specific factual information. It is not well designed for dealing with questions requiring interpretation or exploration, including what is probably the most common, and most important, type of reference inquiry in academic libraries, the open-ended, 'information about' request for assistance with term papers and other classroom assignments. ${ }^{57}$ That is, it works best for questions that are not actually reference questions (e.g., directional queries) and for specific factual requests, which have declined dramatically since users can find such answers themselves online. She also pointed out, "Studies of user behavior indicate that users indeed perceive the reference service as intended for simple questions and quick replies." ${ }^{\not 58}$ Furniture design, the configuration of space, and the queuing model all work together to make many reference desks feel structurally similar to bank teller and fast food lines, venues where customers may have to wait in a short queue but where they assume the service interaction itself will be rather brief. By centering reference services around a desk, Freides 
argued, libraries not only waste librarians' time on “trivial tasks” but also end up encouraging "the assumption that low-level, undemanding" questions are "the service norm." ${ }^{59}$ This led her to the conclusion that the "reference desk is more an impediment than a facilitator" of high quality service. ${ }^{60}$

While some argue that the desk invites and is best suited to handle quick questions, there is also the seemingly contradictory refrain in the literature that although we have seen a decrease in reference desk transactions, "the questions coming to us now tend to be more complex, more time-consuming, and larger in scope." ${ }^{61}$ LaGuardia suggests that this shift to more complex questions is due to the fact that Google "takes care of some first-tier-type questions," but for many users conducting academic research, "the amount of information they have to sift through is immense” and overwhelming. As a result, they need "a thorough introduction to a new methodology of research,” which reference librarians are uniquely equipped to provide. ${ }^{62}$ Fritch and Mandernack also maintain that today’s reference transactions can be very complex, sometimes turning into "mini-instruction sessions, with librarians helping to develop the topic idea, lay out the structure of information...,explain and differentiate between types of information, provide an overview of general search strategies, demonstrate the use of a particular database,... and guide them in presenting their information clearly and appropriately." ${ }^{63}$ Critics would point out, however, that this seems like a great deal to accomplish at a desk that is often inhospitable to in-depth, complex queries and interactions, particularly if other patrons are waiting. Moreover, the reference desk is not an efficient venue for providing instruction to the many students who need it. Rather than helping only those students who ask for it (which is likely a small percentage of the population who actually needs help), and repeating that miniinstruction session for each student individually, the entire class would be better served by 
attending an instruction session. In an hour+ session, each student in the class is likely to learn more than they would in what is usually a far briefer reference transaction. Librarians' time is also used more efficiently, since they can teach the whole class once rather than spending hours repeating themselves to each student individually.

It is important to note here that while the claim that reference transactions are more complex than they once were is decidedly common, ${ }^{64}$ it is also often unsubstantiated. The reality is that most studies show that the majority of questions asked at reference desks are not research questions at all, and of those that are labeled as research queries, only a small percentage are complex enough to require the help of a subject specialist. ${ }^{65}$ Regardless of their number, however, most would agree that public service desks in high-traffic and potentially noisy and distraction-intensive areas of the library generally are not the ideal places to tackle complex research questions. As LaGuardia puts it, "Public desks with ringing phones and users needing to know the locations of rest-rooms and pencil-sharpeners are not conducive spaces for answering this kind of question meaningfully!”66

Research consultations have long been proffered as an ideal way for librarians to work with patrons to address more complex research questions. Summerhill, for example, argues that the best solution to the problems inherent in offering reference services at a public service desk is to make "the majority of librarian/patron time scheduled." ${ }^{67}$ Scheduled consultations have the potential to mitigate what Campbell refers to at the "fifty-five percent problem," or what Ross and Dewdney describe as the "troublesome fact" that whether we "measure reference success by accuracy of the answer or by willingness of the user to return, the success rate for information service hovers in the 50-60 percent range.”68 Attempting to answer questions quickly in a potentially noisy and distracting public service area may have something to do with that dismal 
statistic. LaGuardia maintains that reference librarians need time and space to reflect on complex research problems, and as such, "a private office environment is a better place to do this than a public desk." ${ }^{69}$ Accordingly, she argues that reference service needs to evolve away from the reference desk model and toward a research consultation model "that involves face-to-face meeting away from a public desk combined with e-mail and telephone communications." ${ }^{70}$ This kind of model is necessarily flexible, recognizing that librarians may need some time to conduct research on their own, to experiment with different search strategies and then to get back in touch with the patron later via email, phone, or a scheduled appointment. Research consultations are also a natural extension of library instruction programs. Bell points out that "as students become familiar with subject experts who provide instructional sessions in their courses," they are more likely to go "straight to the librarian they know and trust" rather than to a reference desk. $^{71}$

The Main Library at Brandeis University was an early implementer of an information desk/research consultation model. While Brandeis claimed to have eliminated the reference desk in March of 1990, what they really did was to rename and re-staff it. In other words, a desk remained in a public services area where patrons would bring the same kinds of questions they had always brought to the reference desk. However, the name of the desk was changed to "Information Desk" and it was staffed by graduate students who were charged with 1) answering brief information questions that took no longer than "two or three minutes to convey" and 2) referring research questions to reference librarians. ${ }^{72}$ Patrons with quick questions got them answered immediately at the desk, whereas patrons with more complex research queries were referred to the Research Consultation Service Office. ${ }^{73}$ Referred patrons received professional 
research consultations from librarians in a "quiet and comfortable area” "designed to provide the optimal environment to enhance the client-professional interaction."74

Many have since imitated this model, or aspects of it, seeing in it the potential to improve the quality of interactions between patrons and librarians and to use staff time and expertise more effectively and efficiently. As Rettig notes, “'the Brandeis Model’ was not an isolated effort,” and this "tiered" form of reference, often using paraprofessionals but sometimes students as well, took on various forms, including referrals to on-call librarians. ${ }^{75}$ The Personalized Information Consult Service used by the Prior Health Sciences Library at the Ohio State University is one such variation, and it also illustrates how these models continue to evolve over time. For a time, a staff member at a consolidated reference/circulation public services point would answer basic questions and refer complex questions to librarians who were on call. ${ }^{76}$ However, an appointment model later replaced the on-call system. Other libraries combine their reference service offerings in unique ways. The University of Connecticut's hybrid model, for example, involves some on-call hours as well as desk hours during busier times. ${ }^{77}$ Librarians at Cal State San Marcos do not staff the reference desk but they are on-call. Student assistants work the desk, and call the librarian on the reference cell phone, which helps them "keep track of who is onduty and allows for transfer of this duty between librarians." 78 UC Merced, the newest of the University of California schools, never had a reference desk. Instead, they staff a Library Services desk and a Library Helpdesk with students who are trained to "perform circulation operations, provide basic reference, and refer more complex questions to library staff.”79 Questioning the Mode of DeLIVERy (PHysical VS. VIRTUAL)

Another drawback of a desk-centric reference model is that the desk is bound by time and space while increasingly many of our resources are not. In 1992, Campbell observed that 
traditional reference services were based on a "building-centered, old style, 'make them come to us’ model” that ultimately "cannot survive the information age” given shrinking budgets and increasing user expectations for instant access to electronic information. ${ }^{80}$ Instead of "training the consumer to adapt to what we currently offer," Campbell argued that librarians needed to “focus on what the consumer would like and how we can deliver it." ${ }^{81}$ Libraries have typically been at the forefront when it comes to leveraging the power of information and communication technologies (ICTs) to transcend the limitations of space and time by making their resources available online. Users can access articles, books, and increasingly multimedia resources online, and as such, there is little incentive for many of them to come into the building to conduct research. Universities with fully online programs have also had to ensure that their libraries offer appropriate online resources to support students, many of whom are spread out remotely around the country, and in some cases, around the world. In short, most academic libraries in the United States have built virtual libraries that can meet many if not all of the research needs of their students without them having to enter a library building. As such, it makes little sense to focus our reference services on a public service desk with specific hours in a physical library building.

Some see the addition of email and chat to the panoply of reference services as one important response to the realities of the digital age. LaGuardia, for example, argues that telecommuting is a good way to increase service hours while "reducing library overhead costs.” 82 It is now the norm for many librarians to answer email reference questions from home at night and on the weekends when the reference desk and indeed the physical library is closed, expanding our services into the virtual realm and away from the library building and a specific desk. However, while these transactions are virtual, they still require librarians to function as active human links between users and the information they need. Some critics of traditional 
reference services argue that we can function more efficiently still by using technology to automate many reference exchanges. Campbell, for example, argued in 1992 that "we should set ourselves the goal of answering no less than 75 percent of the questions that currently come to our reference desks using computers and, yes, without human intervention,” delivering these answers “to our users' homes, offices, dorm rooms, or wherever else they may be.” 83 The 75\% figure is somewhat arbitrary, but it is nevertheless roughly consistent with the number of lowerlevel questions that many studies indicate could be answered by students or staff. While having students or staff answer such questions is more cost-effective than having librarians answer them, automating these answers is far more cost-effective still.

\section{THE PERSistence OF THE DESK}

Critiques of the reference desk are clearly not new, and the reasons for abandoning or revamping traditional reference services are many and persuasive. Shifts toward staffing public service desks with students or staff, addressing real reference questions in research consultations rather than at a reference desk, and embracing the potential of technology to automate frequently asked questions are examples of ways that some libraries are attempting to deliver higher quality service in a more efficient manner. Is there evidence to suggest, however, that the literature on the topic has had a significant and widespread effect on reference practices in academic libraries? Have many libraries radically revised or abandoned the desk?

Jackson’s 2002 study reporting on her survey of ARL heads of reference services revealed that though some incremental changes were being made in ARL reference departments, those changes were "not as revolutionary nor as fundamental as many writers have called for." 84 Reference desks had not been eliminated, but they were often staffed differently than in the past, with paraprofessionals assigned to answer simple questions. Similarly, a 2009 study of a subset 
of New Jersey academic libraries that focus on science, engineering, medicine, nursing, or health found that the traditional library reference desk remains the primary mode for delivering reference services, with online reference tools configured as “supplementing” more traditional reference services. ${ }^{85}$

Banks and Pracht's 2008 study surveyed academic libraries that serve between five thousand to fifteen thousand students and found that only two out of 101 libraries surveyed did not have a reference desk at all, $86 \%$ of those surveyed had one reference desk, and the remaining had more than one desk, leading the authors to conclude that having a single reference desk "reflects common operating procedure." ${ }^{86}$ The survey also revealed that while many of the respondents reported declining reference statistics, over $61 \%$ said that their staffing levels remained the same. ${ }^{87}$

Although additional studies are needed to provide a clearer picture of how prominent reference desks are in academic libraries today, the aforementioned articles suggest that Ford's 1986 observation that "the reference desk appears to be a sacred library tradition that many librarians are unwilling or unable to relinquish or question” ${ }^{88}$ remains true of many libraries today. Why then do so many librarians and libraries remain committed to basing reference services “on a piece of furniture known as the reference desk”? ${ }^{89}$ When we have a variety of reference modes at our disposal, why do we continue to implicitly position the reference desk as the "hub" of reference services? ${ }^{90}$ According to Ford, one reason might be "that reference librarians value the service provided at the reference desk much more than do many of the users." 91 Isaacson, for example, argues that reference librarians "provide an indispensable service"; the problem is that we have not "convinced a majority of our users...that librarians are critical to information and knowledge." ${ }^{92}$ Convincing users that they need reference services 
through a variety of outreach and promotional efforts has thus become an important focus of many libraries.

Others argue that the reference desk persists simply because change is difficult for universities in general and libraries specifically. Battin, for example, claims that "the educational institution is one of our society's most conservative institutions,” and that within such institutions there are "strong autonomous vested interests and the fear of losing one’s empire.”93 Reference departments, for example, compete with other departments in libraries for financial and human resources, and as such, they are often focused on convincing the administration that they need additional resources, or at the very least, that it is necessary to preserve the status quo. Assessments that could potentially reveal that some of their services are not necessary might lead to an "unfavorable” reallocation of resources and staff and are thus unwelcome. Additionally, many of our service models have long histories, which also makes change more difficult. As Battin points out, "the weight of our historic traditions is such that we tend to find it very difficult to look at the future in terms of a vastly changed organizational structure.”94

It is perhaps not surprising that some reference librarians resist eliminating the desk, since "reference librarian” has for many become an identity category that is inextricably linked to an activity that they have spent years performing at a desk. Indeed, some academic reference librarians have spent an enormous amount of time at the reference desk, staffing it 10+ hours a week in some cases, a quarter or more of their official time on the job. As those hours accrue over the years, it becomes perhaps less likely that the suggestion that the reference desk should be eliminated will be viewed positively as stemming from a productive desire to facilitate a culture of constant improvement. Rather, it might lead some to infer that much of their life's 
work is being denigrated, that all those years staffing the desk are being positioned as a waste of time. It is no wonder then that such suggestions are resisted.

Others resist getting rid of the reference desk because, as Ford points out, they are “hesitant to eliminate face-to-face personal interaction between librarians and patrons."95 Indeed there are those who valorize the importance of face-to-face interactions between librarians and patrons as intrinsically superior to other less personal forms of communication. Tyckoson exemplifies this tendency, arguing, "Patrons value human contact, and the success of reference service depends on such contact. Like John Henry, I’ll die with my World Book in my hand, Lord, Lord, before I let any expert system beat me down.”96 Elsewhere Tyckoson argues that while libraries have changed dramatically over the years, one constant that will remain is that "personal service will be valued." ${ }^{97}$ He predicts that "in an increasingly impersonal world, the librarian will continue to provide personalized service to patrons," and that it is this personalization that will "differentiate the library from other information providers."98 Critics of the personalization argument point out that many users appear to prefer instant (or at least quick) responses to personalized ones. Moreover, users want answers to come to them. Most would rather receive an automated instant response online rather than having to wait for a librarian to write a personal response via email, or worse yet, having to drive to the library during its hours of operation and potentially wait in line to talk to a librarian.

Another reason for the desk's persistence is that having a desk in a public area does serve a real need. While users increasingly access our resources online, many libraries, particularly newly remodeled, technology-rich ones with collaborative spaces and comfortable furniture, have very high gate counts. Many users do need directional assistance; help with printers, computers, and wireless access; and basic information about how to look-up or find physical 
materials in the library. A smaller percentage of users need more advanced research help. While we should take heed of Lipow's claim that “every question asked at the desk is evidence of the library’s failure to be self-evident,"99 endeavoring to make our physical and virtual resources and services as easy to access and use as possible, we also must acknowledge that for most libraries, this is a process, and we are not quite there yet. As a result, our users do have real questions; the issue becomes what the most effective and efficient strategies are for addressing them.

Finally, some reference librarians are hesitant to abandon the desk because it is not clear to them what they should do with their time that otherwise would have been spent at the desk. Some supervisors might fear the shift as well, since desk hours are a very easy statistic to point to when it comes to accounting for how employees spend their time. The new work that librarians freed from the reference desk will be able to explore is unlikely to be as easily counted as reference desk hours, but many would argue that it is far more pressing and important. Sonntag and Palsson, for example, argue, “Time spent waiting for a question at a desk is better used designing effective instruction programs that have depth in the various majors as well as breadth across all academic programs.” ${ }^{100}$ Bracke, Brewer, Huff-Eibl, Lee, Mitchell, and Ray’s vision is more expansive still, explaining that "new work” might include things like

making sure that the library was a player in scholarly communications issues on campus; shifting our instructional role from simply responding to requests from faculty for single library instruction sessions to a curricular approach to information literacy that also integrates reusable learning objects to eliminate duplicative work; and augmenting revenue flow into the library by radically ramping up grant-seeking activity. ${ }^{101}$

There is no shortage of work to be done, but much of it will require initiative and the ability to get buy-in from and to collaborate with stakeholders across both the library and the campus.

\section{Reference Services @ Cal Poly Pomona}

CPP REFERENCE DESK SERVICE PRIOR TO 2010 
Like many universities across the nation, Cal Poly Pomona continued to staff a reference desk primarily with librarians throughout the first decade of the $21^{\text {st }}$-century, despite the controversies revolving around it in the library literature. However, that is not to say that the desk at CPP has not seen any changes over the years. As the number of transactions declined, double-staffing hours shrank to 11:00 AM to 2:00 PM, Monday-Thursday, until they were eliminated altogether in the middle of the 2008 spring quarter. The name of the desk was also changed from “Reference Desk” to “Research Help Desk” in 2008, a user-centered shift designed to avoid library jargon and to instead employ language that is more meaningful to patrons. As funding continued to decline, part-time librarian positions were eliminated at the end of the 2008 Spring quarter, and with them the weekend and evening reference desk hours that they were hired to cover. After the elimination of part-time librarian positions, the desk was staffed by nine full-time tenured and tenure-track librarians and two library assistants. However, librarians with special responsibilities (e.g., Instruction Coordinator, Collection Development Coordinator, Head of Public Services, and the HSI Grant Administrator) worked fewer reference desk hours, spreading the limited reference desk staff thinner still. The retirements of a librarian and a library assistant in 2009 and 2010 led to further staffing shortages and decreases in total reference desk hours. With subsequent retirements on the horizon and no real prospect of filling vacated positions due to the budget crisis, it was clear that traditional reference desk services and staffing patterns needed to be re-envisioned.

\section{THE LIBSTARS PROGRAM IS BORN}

Although reference desk transactions have declined dramatically at the CPP University Library over the last 20 years, the Research Help Desk still receives thousands of queries every year. It thus serves a purpose, but statistics also indicate that like many of the reference desks 
studied in the library literature, our desk receives a preponderance of questions that do not require the attention of a librarian, including directional, printing, technology, and basic research (e.g., title look-up) queries. As a result, we were unwilling to abandon a desk altogether, since our users have real questions, however basic. Moreover, users with more complex queries who come into the building often need a point of contact to help them get in touch with a librarian, and the Research Help Desk serves that purpose. However, we also concluded that the time of our ever shrinking population of librarians would be better spent working on projects that required their expertise and experience rather than sitting and waiting for questions or explaining the intricacies of printing. On the other hand, we also value and enjoy the professional face-toface research help we provide students as reference librarians, so we were unwilling to completely untether librarians from the desk. Instead, we developed a program that would lengthen the chord, thereby making the most effective use of the librarians' time and enabling them to answer actual research questions in a space that is more conducive to in-depth help than the reference desk. In short, we decided on a variation of the Brandeis model. Although the desk is still called the Research Help Desk in order to advertise to users that we do provide research help at the library, the desk functions very much like Brandeis’ information desk, where welltrained students “provide quick information, screen questions, and refer users to reference librarians.”102

In the fall of 2010, the CPP University Library implemented our Library Student Assistant Research Support (LibStARS) program. ${ }^{103}$ Three students were hired to staff the Research Help Desk a total of 40 of the 47 hours that the desk is open per week. The 40 hours are split among the students, with each student working on the desk independently. However, they are not totally alone, since like the Brandeis model, a backup librarian is scheduled for 
every hour a student is on the desk, though our librarians stay in their offices rather than relocating to a separate "Research Consultation Service office." 104

As the person responsible for hiring and supervising the LibStARs, I believed that the success of the program would hinge upon hiring students with a specific skill set. I initially looked for applicants with customer service experience and grade point averages that indicated that they were intelligent and able to manage their time well, but the most important trait that I ultimately focused on was excellent social skills. I wanted to hire students who exuded friendliness and approachability, qualities that, in addition to their peer status, I believed had the potential to increase visits to the desk. Anecdotally, many librarians have observed that students seem to feel more comfortable approaching peers than non-peers. Howe and Strauss indicate that this peer preference is typical of the Millennial generation (also frequently referred to as Generation Y and the Net Generation) who now inhabit our campuses and that these students tend to develop "strong team instincts and tight peer bonds." 105 In their conversations with teachers, Howe and Strauss also found that compared with Gen X students, Millennials "get along less well with teachers but better with one another." ${ }^{\text {"106 }}$ Similar findings have been reported in the library literature. Manuel claims that "Gen Yers usually find peers more credible than teachers," 107 and Gardner and Eng have observed "that when both a student worker and a librarian are at the desk, student patrons will almost always approach the student worker first.” 108 Additionally, OCLC’s 2005 report on college students' perceptions of libraries indicated that $67 \%$ of students learned about electronic information sources from friends whereas $33 \%$ learned about them from librarians. ${ }^{109}$ Given Millennial students’ preference for peers, I anticipated that friendly and outgoing Library Student Assistant Researchers (LibStARs) might have a certain advantage over librarians, potentially generating more desk traffic. 
Because choosing the right LibStARs was so important, the interviews were rigorous, consisting of 12 questions that were designed to ascertain the students’ reliability, enthusiasm, and service-oriented attitude, as well as their ability so speak clearly, to expand upon their points and provide examples, and to come across as friendly and outgoing. The interview process thus conveyed to the students immediately how important the librarians perceive this job to be and that they would be among an elite group should the library extend them a job offer. In short, I made it clear that it was an honor to be selected as a LibStAR and that the librarians had very high expectations, all of which made the students proud to be chosen and eager to rise to the level we set for them.

Training was equally critical to the success of the program, ensuring that the new LibStARs answered and referred questions appropriately so that librarians could feel confident that our patrons were getting their needs met without the presence of a librarian on the desk. To that end, LibStARs received extensive training on how to answer directional, printing/copying, facility and services, and basic research questions (which include tasks like searching for a title in the catalog, accessing a specific database on the library homepage, and helping patrons find a book on the shelf) as well as how to refer questions appropriately to back-up librarians. An online training portal was developed to streamline and systematize the training process. Training materials focus on customer service, the library’s resources and services, basic research skills, and the basic reference interview. The modules include reading material and video tutorials as well as interactive activities that we completed as a group over several days.

Training the LibStARs to refer questions appropriately was particularly important. Reference librarians decided that they wanted all research questions that went beyond a simple title lookup to be referred to librarians. A referral flowchart helped the LibStARs conceptualize 
the referral process, but the most important part of the training was the role-playing exercises, which required them to translate what they learned into actual practice. The three LibStARs took turns being the patron and being the LibStAR, while one observed. I gave the LibStAR playing a patron a question, and then they proceeded to role-play the transaction. In most cases, I would let the transaction come to a close without interruption, and then I would facilitate a group discussion about what the student playing the LibStAR did well and what could be improved upon.

Specifically, LibStARs are taught a modified version of the reference interview; they are trained to ask: “Are you doing research for a class?” If the answer is "Yes,” they determine which class and what the general parameters of the assignment are so that they can provide a smooth service transition to the backup librarian. Students alert the librarian that there is a research question that requires their attention by using the reference desk phone to call the backup librarian in his/her office. The librarians’ offices are located in an office suite directly behind the Research Help Desk, making it easy for them to go out to the desk to help the student at a separate computer located there if the question is not particularly complex or to bring them back to their office to work together in a quieter environment.

After answering or referring a question, LibStARs record the transaction in an online log. Initially we used a homegrown system developed using a Google form to log questions. Only LibStARs, and not librarians and library staff, logged questions, as the purpose of the log was to monitor the students' answers, providing instructional interventions when questions could be answered or referred more effectively. The log thus facilitated a flexible, ongoing, as needed training program. The following year the library implemented LibAnswers’ Reference Analytics module, using it to record all transactions handled by all reference staff and asked from any 
locale. LibStaRs now only record transactions that they answer and not those that they refer. Librarians and library staff record questions that were referred to them, noting who referred the question in a pre-defined field. Reference Analytics thus serves as the central place where we now record all statistics, but it also facilitates the continued monitoring and training of the LibStARs as well.

Additionally, the training program required the LibStARs to complete a pre and post readiness inventory on their basic library research knowledge. At the end of the initial formal training program, they signed a training checklist, certifying that they had successfully completed all of the online training modules. Finally, students submitted a training evaluation form, which gave me the opportunity to learn from them about what worked and did not work so well for them in their training and to make appropriate adjustments to the training program as needed. After their formal training, the LibStARs shadowed librarians at the Research Help Desk for over a month before being left alone on the desk. Even when they were alone, however, there was always a librarian on-call in an office just a few feet away to answer research questions and to provide support as needed.

\section{ASSESSMENT OF THE LIBSTARS PROGRAM}

At the end of the first year (2010-2011), the LibStARS program was assessed by 1) surveying three key constituencies—patrons, librarians, and LibStARs—and 2) analyzing the question log.

PATRON SURVEY

Patrons were asked to take an online survey after having been helped by a LibStAR at the desk. A total of 55 patrons agreed to take the survey, including 47 undergraduates, five graduate 
students, one faculty member, and two patrons who identified themselves as “other.” Responses indicated the following:

- Approachability: 98\% of the patrons found the LibStARs very approachable or approachable

- Helpful: $96 \%$ found them very helpful or helpful

- Peer Help: 45.5\% indicated that they would be more likely to ask for help from a peer working at the Research Help Desk. 49\% said they had no preference. 5\% indicated they would be more likely to ask for help from someone who was not a peer.

- Satisfaction: $96 \%$ indicated that they were very satisfied or satisfied with the help they received.

- Returning Customers: 94\% indicated that they would be very likely or likely to use the Research Help Desk again.

Although the pool was small, the respondents confirmed my observations as the LibStARs' supervisor that they were doing a good job coming across as approachable and helpful and providing our patrons with an experience that satisfied them. When asked to explain why they would be likely or unlikely to ask for help again at the Research Help Desk, the most common patron responses were that they would be likely to ask for help again because of how “approachable,” "helpful, “friendly,” and "kind” the LibStARs were. The few who indicated that they might not ask for help again explained that this was not because they had a bad experience at the desk but rather because they "usually do not need help" and "could probably figure it out on my own in most casis [sic].” It was also interesting to note that while just under half of the respondents were more likely to ask for help from a peer, only 5\% were more likely to ask for help from someone who was not a peer, adding additional evidence to support the idea that very 
few students would prefer approaching a desk staffed by a librarian than one staffed by a student. One respondent indicated that the LibStAR on duty was "in one of my classes, so I felt more comfortable talking to her.”

\section{LIBRARIAN SURVEY}

The next constituency surveyed was the librarians. Prior to the advent of the LibStARS program, some librarians had expressed concern about the wisdom of staffing a desk with students; they worried that questions would not be answered and referred effectively. However, by the end of the first year of the program, all librarians who filled out the survey reported that they found the students to be very approachable and helpful. Six out of seven indicated that they believed the LibStARS were effective in referring questions, with one undecided. All librarian respondents reported that they were satisfied or very satisfied with the system of having LibStARs answer non-research questions and refer research questions to backup librarians. One librarian wrote in the comments section of the survey: "Although during my schedule as backup I cannot leave my desk, it is still very helpful for getting desk work done, mostly uninterrupted. I would not have the level of focus and concentration at the Ref Desk, and I appreciate their scheduled hours at the Ref Desk.”

\section{LIBSTARS SURVEY}

Finally, the LibStARs themselves were also surveyed. Results indicated that the

\section{LibStARS:}

- Felt their training prepared them to effectively answer and refer questions

- Felt they were an important part of the Research Help Desk Team

- Were very satisfied with their jobs 
- Were very confident or confident with their ability to answer questions and refer research questions appropriately

- Were comfortable calling their backup librarians.

The LibStaRS also felt that the peer aspect of the program was particularly valuable. When asked “How do you think being close in age to many of our patrons affects your interactions with them? Does this closeness in age seem generally to be an advantage or disadvantage?” all LibStARs maintained that being around the same age as most of our patrons was an advantage because students tended to feel more comfortable with them than with the librarians. One LibStAR reported: "If you observe how students interact with other students as opposed to the librarians, they are more likely to engage in conversation and seem to participate more during research. I honestly think it's because we as peers are going through the same things that they are right now (tests, papers, lectures, etc.) and they feel like we relate more to them.” Another LibStAR pointed out not only that students feel more comfortable around the LibStARs but also that the LibStARs sometimes have knowledge about classes and the campus that the librarians lack:

There are patrons that seem to act the same around their friends as when they ask me questions; they are comfortable, they approach me with confidence and are not nervous. They also ask me questions that only a student would know; such as questions about professors or other advice like what's the best place to eat here (sometimes random questions). Another thing would be that patrons seem to find it easier to tell me about their research project and I've noticed is that they hold back information when I call the back up librarian. Once I catch this, I tell the librarian the extra information the patron has not told him/her.

\section{TRANSACTION LOG REVIEW}

In addition to conducting surveys, we assessed the first year of the LibStARs program by reviewing the transaction log. With few exceptions, students answered questions accurately. They also usually referred questions appropriately but sometimes they had a tendency to be too 
helpful. For example, for a period, they started helping students find books on their topics rather than referring them right away to the librarian. Oddly, they were not repeating this behavior with articles. Once this pattern was ascertained, they were reminded to always ask if the patron is doing research for a class and if so, to call the back-up librarian. One thing that we noticed when examining their incorrect referrals, however, is that they generally provided accurate answers to the questions that policy dictated that they should have referred. This raised the question of whether we were asking too little of them. Allowing students to take the patron as far as they could and then calling the backup librarian when they got stuck could potentially free up additional librarian time. We have not implemented a new policy, however, since some librarians share the frequently expressed reference librarian concern, articulated here succinctly by Miller, that students and non-librarians will not be able to "perceive the complex needs which so often lie just below the surface of apparently simple inquires." 110

\section{LIBANSWERS}

Another change to our reference program came in the form of Springshare's LibAnswers. ${ }^{111}$ LibAnswers is a significant step forward toward answering Campbell's call for automated systems that answers many of the questions that currently come to our reference desks. ${ }^{112}$ In order for LibAnswers to be able to effectively automate some reference transactions, however, librarians first have to populate its knowledge base with question/answer pairs. СРP librarians used their own experience to identify frequently asked questions and then to devise effective responses to them. They also incorporated information into question/answer pairs that had been scattered across the library website, making it easily discoverable in one central knowledge base. When patrons type their queries into the FAQ box on the library homepage, using either natural language or keywords, the LibAnswers widget generates suggestions as they 
type. When patrons see their question or a similar one, they simply click on it to get their answer. Librarians construct an answer once, and then the system automates the connection between the information and the patron who needs it. LibAnswers is thus an important step toward lessening the repetitive nature of reference work (i.e., constantly repeating answers to frequently asked questions), freeing up librarians to answer more complex queries or to perform other tasks that are more aligned with their expertise.

The CPP LibAnswers knowledge base is also continuously expanding as the result of the actions of our users. When students do not find answers to their questions in the knowledge base, they have the opportunity to fill out an email form, which upon submission, is emailed to all Reference, Instruction, and Collection librarians. The first librarian available who feels capable of answering the question simply logs into the system, answers the question, and submits it, at which point the answer is emailed to the patron. In our case, we also have it set up so that the answer is emailed to all librarians, which not only lets us know without having to login to the system that the question has been answered, but also allows us to learn from each other by observing the different ways we approach questions. Initially these email transactions are marked as private and are not included in the public LibAnswers knowledge base. However, librarians can select private questions that they think other patrons are likely to have as well, edit and revise them as appropriate, taking out any identifying patron information, and then add them to the public knowledge base.

Because LibAnswers allowed us to add an automated reference component to our online reference services, total online reference transactions (email, chat, and now LibAnswers) for the year shot up 210\%, from 1682 in 2009/10 to 5220 in 2010/11. Whereas online reference transactions made up approximately $10 \%$ of all total reference transactions in 2009/2010, they 
accounted for 28\% of all total reference transactions in 2010/2011. Automated LibAnswers transactions were responsible for this dramatic increase, as they accounted for $71 \%$ of the total online transactions.

Some librarians might hesitate to count the "Direct match via auto-suggest” and "Clicked on" statistics ${ }^{113}$ that LibAnswers provides as reference transactions, since they do not involve a direct interaction between a patron and a librarian. The librarian will generally not even be aware of the transaction at the time of its occurrence. However, failing to count these interactions as reference transactions ignores the important and effective reference work that has gone on behind the scenes to help patrons find answers to their queries. Specifically, librarians have written answers to frequently asked questions, selected a user-friendly interface (the LibAnswers widget) to make it easier to discover answers to these common questions, and uploaded the question answer pairs into the system, thereby facilitating the connection between our patrons and the information they need. Failure to track these statistics would constitute a failure to value the efficient and seamless medium through which we have both provided answers to patron queries and taken a step toward eliminating duplicative work (answering the same questions ourselves over and over again).

Others might point out that many of the questions (though certainly not all) in the knowledge base are not research questions per se, and thus they do not rise to the level of the definition of reference outlined by Summerhill and RUSA. While this is true, these directional, technology, printing, and other facility and service queries are nevertheless precisely the types of questions that are frequently fielded and tracked at reference desks. They are simply being handled more efficiently through LibAnswers. That is, many patrons can get their questions answered immediately, 24/7, at the point of need, wherever in the world they happen to be. 
When patrons do not find relevant answers to their queries in the knowledge base, they do not have to search the website in an effort to find an appropriate librarian to email. They are instead immediately directed to a form that allows them to seamlessly email their query to all librarians. More complex queries might require some back and forth, which the system can facilitate, or the librarian can choose to continue the reference exchange via personal email or by scheduling a face-to-face appointment. This is patron-centric (rather than desk or library-centric) reference service at its most effective and efficient, and we should be tracking the results.

\section{CONCLUSION}

In sum, our assessment of the LibStARS program indicates that it benefits librarians, students, and LibStARs alike. Specifically, the LibStARS program allows librarians to use their time more efficiently and cost-effectively. Rather than sitting and waiting at a desk where the majority of questions asked could be effectively handled by students, librarians are instead able to focus their time on projects that require their expertise and experience, such as creating research guides, tutorials, and other learning objects and pedagogical tools that can be used online or in face-to-face classes; working with other campus constituencies to ensure that the library is involved in scholarly communications issues on campus; curating unique digital collections; working on affordable learning solutions projects on campus; researching and writing grants; researching and writing articles and preparing for presentations; etc. However, when a research question arrives at the desk, librarians' research expertise continues to be utilized on demand, at the point of need.

The LibStARS program also allows the library to leverage the benefits of peer learning. Feedback collected from surveys of both patrons and the LibStARs lend additional evidence to support the idea that many students prefer soliciting help from peers than non-peers. Our 
friendly, service-oriented LibStARs thus strike many of our patrons as more approachable than non-peer librarians, making it more likely that they will feel comfortable coming to the desk with their queries. The LibStARs themselves are also learning through their interactions with peers, improving their knowledge of the library’s resources and services and refining their communication and customer service skills.

The LibStARS program has also provided librarians with the opportunity to develop more sustained and meaningful relationships with students than their jobs usually allow for. Working at the Research Help Desk and/or teaching library instruction sessions, librarians have plenty of contact with students, but they tend to be more impersonal one-shot experiences. Librarians who do not teach quarter or semester long classes simply do not have the opportunity to get to know and thus impact the lives of students in the same way that many professors do. LibStARs are an exception, as they train with librarians, shadow them after their official training is complete, and then interact with and refer questions to them daily. The program thus facilitates the development of personal relationships between librarians and students that in turn helps students academically and in some cases professionally as well. Indeed, one unanticipated benefit of the LibStARS program is that it has helped students explore a career path that they might not have known much about or even considered. Two of the three LibStARs graduated at the end of our 2010-2011 pilot year and both enrolled in Master’s degree programs in Library and Information Science. The third LibStAR from the program's first year is also considering pursuing a library degree after completion of her Master's degree in English. Two new LibStARs were hired for the second year of the program, and one of those is now enrolled in library school. The LibStARS program was thus effective not only in training undergraduates to be effective student workers but also in inspiring some of them to work toward becoming future colleagues. 
The implementation of our LibAnswers system has benefitted our patrons as well, providing them with instant, 24/7 access to common questions, circumventing the time and space limitations of the traditional reference desk as well as the usability issues that make traditional html FAQ pages difficult to navigate. LibAnswers is also helping the library to save time and money by freeing up library staff from repeatedly answering common questions, giving them more time to focus on other work that is consistent with their experience and expertise.

Additionally, the system allows us to track the questions that students are asking but not finding answers to and then navigating away rather than filling out the form. Reviewing these questions allows us to populate the knowledgebase with additional question/answer pairs that will be useful to our patrons. The more question/answer pairs we include in the ever-growing knowledge base, the more patrons we are able to assist as efficiently as possible. 


\section{NOTES \& REFERENCES}

1. Barbara J. Ford, "Reference beyond (and without) the Reference Desk," College \& Research Libraries 47, (September 1986): 493.

2. Karen Storin Summerhill, “The High Cost of Reference: The Need to Reassess Services and Service Delivery,” Reference Librarian 43 (January 2, 1994): 82-83.

3. Ibid., 80.

4. Keith Ewing and Robert Hauptman, "Is Traditional Reference Service Obsolete?” Journal of Academic Librarianship 21 (January 1995): 3.

5. David W. Lewis, “Traditional Reference is Dead, Now Let's Move on to Important Questions,” Journal of Academic Librarianship 21, (January 1995): 12.

6. Reference to: Monty Python and the Holy Grail, DVD, directed by Terry Gilliam and Terry Jones (1975; Culver City, CA: Columbia Tri-Star Home Entertainment, 2001).

7. Steven J. Bell, “Who Needs a Reference Desk?” Library Issues 27, no. 6 (July 2007), http://www.libraryissues.com/sub/LI270006.asp. 1-4 (accessed August 30, 2012).

8. Gabriela Sonntag and Felicia Palsson, "No Longer the Sacred Cow - No Longer a Desk: Transforming Reference Service to Meet 21st Century User Needs," Library Philosophy and Practice (January 2007): http://unllib.unl.edu/LPP/sonntag-palsson.pdf (accessed August 30, 2012).

9. Summerhill, “The High Cost,” 72.

10. William Miller, "What's Wrong with Reference: Coping with Success and Failure at the Reference Desk,” American Libraries 15, no. 5 (May 1984): 303.

11. Ibid., 304. 
12. Ibid., 303.

13. Scott Carlson, “The Deserted Library,” Chronicle Of Higher Education 48, no. 12 (November 16, 2001), A35.

14. Andrew Richard Albanese, “Deserted No More,” Library Journal 128, no. 7 (April 15, 2003): 34.

15. The word "rebounding” in this sentence alludes to the highlighted line beneath the title of Albanese’s article that reads: “After years of declining usage statistics, the campus library rebounds.”

16. Charles Martell, “The Ubiquitous User: A Reexamination of Carlson's Deserted Library,” portal: Libraries \& the Academy 5, no. 4 (October 2005): 443.

17. Ibid., 445-446.

18. Marianne Stowell Bracke, Michael Brewer, Robyn Huff-Eibl, Daniel R. Lee, Robert Mitchell, and Michael Ray, “Finding Information in a New Landscape: Developing New Service and Staffing Models for Mediated Information Services,” College \& Research Libraries 68, no. 3 (2007): 248.

19. Cal Poly Pomona, “About Cal Poly Pomona: A Brief Mélange of History, Quick Facts, and Philosophy,” http://www.csupomona.edu/about.php (accessed August 30, 2012).

20. Total reference transactions in 1990/91 were 74,463 and in 2010/11 they were $18,517$.

21. Cheryl LaGuardia, “The Future of Reference: Get Real!” Reference Services Review 31, no. 1 (2003): 40. 
22. Jerry D. Campbell, “Clinging to Traditional Reference Services: An Open Invitation to Libref.com,” Reference \& User Services Quarterly 39, no. 3 (April 15, 2000), under “The .Coming of Education,” OmniFile Full Text Mega (H.W. Wilson), EBSCOhost. 23. Ibid.

24. Susan M. Ryan, “Reference Transactions Analysis: The Cost-Effectiveness of Staffing a Traditional Academic Reference Desk,” Journal Of Academic Librarianship 34, no. 5 (September 2008): 389.

25. Bell, “Who Needs a Reference Desk?” under “Adapting to Millennial Generation Students.”

26. Sonntag and Palsson, “No Longer the Sacred Cow,” under “Aligning Our Objectives.”

27. Martell, “The Ubiquitous User,” 444.

28. Ibid.

29. See LibAnswers section of the article for more on what accounts for this increase.

30. Miller, “What’s Wrong with Reference?” 303.

31. Ibid., 322.

32. Julie Garrison, “What Do We Do Now?: A Case for Abandoning Yesterday and Making the Future,” Reference \& User Services Quarterly 51, no. 1 (Fall2011 2011): 12.

33. Summerhill, “The High Cost,” 73.

34. Ibid., 74.

35. Reference and User Services Association (RUSA), “Definitions of Reference,” January 14, 2008, http://www.ala.org/rusa/resources/guidelines/definitionsreference (accessed August 30, 2012). 
36. Ibid.

37. Ewing and Hauptman, “Is Traditional Reference Service Obsolete?” 3.

38. Jeffrey W. Saint Clair, Rao Aluri, and Maureen Pastine, "Staffing the Reference Desk: Professionals or Nonprofessionals?” Journal of Academic Librarianship 3, no. 3 (July 1977): 149.

39. "In September, one of the busiest months, the reference desk fielded just over 4,400 questions. Of those, 243 involved extensive interaction and research, about 2,300 were simpler reference questions, and more than 1,800 were deemed 'directional'--that is, pointing to the stacks, the computers, or the nearest toilet.” Scott Carlson, “Are Reference Desks Dying Out?” Chronicle Of Higher Education 53, no. 33 (April 20, 2007), under “At the Heart,” Academic Search Premier, EBSCOhost (accessed July 19, 2012).

40. Bracke and others, “Finding Information in a New Landscape,” 253.

41. Ryan, “Reference Transactions Analysis,” 395.

42. Ibid.

43. Carlson, “Are Reference Desks Dying Out?”

44. Bell, “Who Needs a Reference Desk?” under “Time to Respond to Decline and Change.”

45. Summerhill, “The High Cost,” 74.

46. Bell, “Who Needs a Reference Desk?” under “Time to Respond to Decline and Change.”

47. Ewing and Hauptman, “Is Traditional Reference Service Obsolete?” 3.

48. Ibid.

49. Ibid., 6. 
50. Summerhill, “The High Cost,” 71.

51. Ibid., 83.

52. Ibid., 77.

53. Ibid., 77.

54. Ibid., 82.

55. Ryan, “Reference Transactions Analysis,” 396.

56. Ibid., 397-8.

57. Thelma Freides, “Current Trends in Academic Libraries,” Library Trends 31, no. 3 (Win 1983): 467.

58. Ibid.

59. Ibid.

60. Ibid.

61. LaGuardia, “The Future of Reference,” 40.

62. Ibid., 40-41.

63. John W. Fritch and Scott B. Mandernack, “The Emerging Reference Paradigm: A Vision of Reference Services in a Complex Information Environment,” Library Trends 50, no. 2 (October 15, 2001): 294-95.

64. Many writers state that questions have gotten more complex and time-consuming, though few provide substantive evidence to support this claim. For example, Bell states, "While individuals may easily locate factual content with search engines, they often conclude that using these same tools for comprehensive research is an exercise in frustration. Those more complex research questions are the ones they ask at the reference desk.” Bell, "Who Needs a Reference Desk?” under “Time to Respond to Decline and Change”; Fritch and Mandernack argue, “The 
reference transactions that remain may more than make up for the loss of others due to the complexity of the questions.” Fritch and Scott B. Mandernack, "The Emerging Reference Paradigm,” 294; Hisle claims, “reference librarians report that reference questions now tend to be more complex, albeit fewer in number." Lee W. Hisle, "Reference Questions in the Library of the Future,” Chronicle of Higher Education 52 (6) (September 30, 2005): B7; Jackson observes, "Anecdotally, librarians seem to agree that there are fewer questions being asked at the reference desk, but that the questions are generally more complicated, taking more time and often requiring that the librarian move away from the reference desk and out to the users.” Rebecca Jackson, “Revolution Or Evolution: Reference Planning in ARL Libraries,” Reference Services Review 30, no. 3 (January 3, 2002): 212; LaGuardia maintains, "But the questions coming to us now tend to be more complex, more time-consuming, and larger in scope.” LaGuardia, "The Future of Reference,” 40; Tenopir provides sample quotes that purportedly capture typical librarian sentiments, such as "our statistics are down and our workload is up. We can do more so each question takes longer as we explore and teach the varied resources." Carol Tenopir, "Reference Use Statistics,” Library Journal 123, no. 8 (May 1998): 32.

65. See for example Bracke and others, "Finding Information in a New Landscape,” 253; Carlson, “Are Reference Desks Dying Out?” under “At the Heart”; Ryan, “Reference Transactions Analysis,” 389-399.

66. LaGuardia, “The Future of Reference,” 41. Bell concurs: “Contemporary questions often require in-depth consultations and the reference desk, often situated in a noisy, high-traffic area, can be an ill-suited location for this task.” Bell, "Who Needs a Reference Desk?” under “Time to Respond to Decline and Change.”

67. Summerhill, "The High Cost,” 80. 
68. Catherine Sheldrick Ross and Patricia Dewdney, “Negative Closure,” Reference \& User Services Quarterly 38, no. 2 (Winter 1998): 151. Academic Search Premier, EBSCOhost (accessed August 14, 2012).

69. LaGuardia, “The Future of Reference,” 41.

70. Ibid., 41.

71. Bell, “Who Needs a Reference Desk?” under “Adapting to Millennial Generation Students.”

72. Virginia Massey-Burzio, "Reference Encounter of a Different Kind: A Symposium,” Journal of Academic Librarianship 18, no. 5 (November 1992): 278.

73. Ibid., 277.

74. Ibid., 279.

75. James Rettig “Reference Service: From Certainty to Uncertainty,” Advances In Librarianship 30 (January 2007): 120.

76. Stephanie J. Schulte, “Eliminating Traditional Reference Services in an Academic Health Sciences Library: A Case Study,” Journal of the Medical Library Association 99, no. 4 (October 2011): 273-4.

77. Scott Kennedy, “Farewell to the Reference Librarian,” Journal of Library Administration 51, no. 4 (May 2011): 323.

78. Sonntag and Palsson, "No Longer the Sacred Cow,” under "Moving in Together.”

79. Sara Davidson and Susan Mikkelsen, “Desk Bound No More: Reference Services at a New Research University Library,” Reference Librarian 50, no. 4 (October 2009): 347.

80. Jerry D. Campbell, "Shaking the Conceptual Foundations of Reference: A Perspective,” Reference Services Review 20, no. 4 (January 4, 1992): 32. 
81. Ibid., 33.

82. LaGuardia, “The Future of Reference,” 41.

83. Campbell, "Shaking the Conceptual Foundations," 31.

84. Jackson, "Revolution or Evolution,” 226.

85. Patricia H. Dawson, “Are Science, Engineering, and Medical Libraries Moving away from the Reference Desk? Results of a Survey of New Jersey Libraries,” Science \& Technology Libraries 30, no. 4 (September 2011): 351.

86. Julie Banks and Carl Pracht, “Reference Desk Staffing Trends: A Survey,” Reference \& User Services Quarterly 48, no. 1 (Fall2008 2008): 56.

87. Ibid., 56.

88. Ford, "Reference beyond (and without)," 491.

89. Summerhill, “The High Cost,” 83.

90. Freides, “Current Trends in Academic Libraries,” 466.

91. Barbara Ford, "From Discussion to Action: Changing Reference Service Patterns,” Journal of Academic Librarianship 18, no. 5 (November 1992): 285.

92. David Isaacson, “What's Still Wrong with Reference,” Library Journal 132, no. 19 (November 15, 2007): 41.

93. Patricia M. Battin, “The Library: Centre of the Restructured University,” Scholarly Publishing 17, (April 1986): 256.

94. Ibid.

95. Ford, "Reference beyond (and without)," 493.

96. David A. Tyckoson, “What's Right with Reference,” American Libraries 30, no. 5 (May 1999): 58. 
97. David A. Tyckoson, “On the Desirableness of Personal Relations between Librarians and Readers: The Past and Future of Reference Service,” Reference Services Review 31, no. 1 (January 2003): 15.

98. Ibid.

99. Anne Grodzins Lipow, “The Librarian Has Left the Building — But To Where?” Internet Reference Services Quarterly 8 (2003): 15.

100. Sonntag and Palsson, “No Longer the Sacred Cow,” under “Aligning Our Objectives.”

101. Bracke and others, “Finding Information in a New Landscape,” 259.

102. Ford, “From Discussion to Action,” 285.

103. The acronym is spelled two ways. When referring to the program, we use LibStARS, for Library Student Assistant Research Support. When referring to the student assistants as a group they are LibStARs, Library Student Assistant Researchers. The LibStARS program has its own website: http://www.csupomona.edu/ library/reference/libstars.html

104. Massey-Burzio, “Reference Encounters of a Different Kind,” 277.

105. Neil Howe and William Strauss, Millennials Rising: The Next Great Generation (New York: Vintage, 2000), 44.

106. Ibid., 181

107. Kate Manuel, “Teaching Information Literacy to Generation Y,” Journal of Library Administration 36, no. 1/2 (January 2002): 208.

108. Sudan Gardner and Susanna Eng, "What Students Want: Generation Y and the Changing Function of the Academic Library,” Portal: Libraries \& The Academy 5, no. 3 (July 2005): 413. 
109. Cathy De Rosa, Joanne Cantrell, Diane Cellentani, Janet Hawk, Lillie Jenkins, and Alane Wilson. Perceptions of Libraries and Information Resources: A Report to the OCLC Membership (Dublin, Ohio: OCLC Online Computer Library Center, 2005), 1-19, http://www.oclc.org/reports/pdfs/Percept_all.pdf (accessed August 30, 2012).

110. Miller, “What’s Wrong with Reference?” 306.

111. For more information about LibAnswers, visit Springshare’s LibAnswers’ website: http://springshare.com/libanswers/.

112. Campbell argues that reference librarians should set a goal of "answering no less than 75 percent of the questions that currently come to our reference desks using computers and, yes, without human intervention.” Campbell, "Shaking the Conceptual Foundations,” 31.

113 Both statistics indicate that users clicked on questions that they found relevant to their own queries. 